\title{
With increasing age at tumor diagnosis in familial cancer: Cancer is limited to fewer organs
}

\author{
Håkan Olsson ${ }^{1, *}$ \\ 1 Department of Oncology and Pathology and Cancer Epidemiology, Clinical Sciences, Lund University, Lund, S-221 85, Sweden
}

\begin{abstract}
Hereditary cancer that has monogenic inheritance affects every tenth patient, on average, who is diagnosed with cancer, and it has been suggested, based on twin studies, that approximately $30 \%$ of all cancer patients have a genetic predisposition to developing cancer. In this article, the author posited that familial syndromes become more organ specific with increasing age at tumor presentation to the point that very late in life, only a few organs are affected by tumors. The reason for this could be that the tumor originates from a more differentiated, organ-specific progenitor/stem cell later in life, while the progenitor/stem cell might be involved in organogenesis in different organs earlier in life. Examples are given for skin cancer, colon, endometrial and breast cancer. Patients with familial cancer who present with cancer at an older age have a more organ-restricted disease. This could be because the tumor has a more differentiated progenitor/stem cell origin. Examples are given for families with breast cancer, melanoma, non-melanoma skin cancer, endometrial and colon cancer.
\end{abstract}

Keywords: hereditary cancer; familial syndromes; stem cell origin of the tumor

\section{Introduction and hypothesis}

Hereditary cancer that has a monogenic inheritance affects fewer than every tenth patient diagnosed with cancer, and it has been suggested in twin studies that approximately $30 \%$ of all cancer patients have a genetic predisposition for cancer [1, 2]. Presently, it is unknown why different predisposing genes or familial syndromes affect the cancer risk according to the different organ patterns. In this article, the author hypothesized that familial syndromes become more organ-specific with increasing age at tumor presentation; as a result, only a few (or one) organs are affected by tumors.

\section{Materials, methods and results}

\section{Familial/hereditary cancer supporting the hypothesis}

In a population-based study from the Swedish cancer registry of patients with 4 or more tumors of which at least one was melanoma, individuals and families who presented with melanomas alone or a mixture of nonmelanoma skin cancers and melanomas late in life were evaluated. Tumors presenting earlier in life affected a more diverse set of organs in the individual and family, such as presenting as adenocarcinoma in different organs or as brain tumors [3, 4].

Comparing families with melanoma who had a CDKN2A mutation with families with wild type CDKN2A, CDKN2A families had an earlier age at tumor diagnosis, and several organs (e.g., skin, upper Gl, lung, breast, and pancreas) were affected by a tumor, while the wild type families only had melanomas or non-melanoma skin cancer late in life $[5,6]$.
Patients carrying the BRCA1 mutation also have a high risk for breast and ovarian cancer, and patients with the BRCA2 mutation have a high risk for breast, ovarian, prostate and pancreatic cancer and melanoma. Wild type BRCA families often present with breast cancer late in life [7]. The breast tumors in wild type families are often hormone receptor positive [8]. Breast cancer in families carrying a predisposing p53 germline mutation (Li Fraumeni syndrome) presents at a very early age, and mutation carriers can present with tumors in other organs, such as the soft tissue, brain, adrenal gland and hematopoietic system [10]. Studies of other tumor types (Table 1) for this hypothesis are scarce, and only indirect data thus far support it.

Patients who have a germ line mutation in any of the mismatch repair genes have the hereditary non-polyposis colon cancer syndrome (HNPCC), and they can present with tumors that affect a number of organs, such as the colon, rectum, and other parts of the GI tract, endometrium and urinary tract. Wild type colon cancer families generally

*Corresponding author: Håkan Olsson, MD, PhD., Department of Oncology and Pathology and Cancer Epidemiology, Clinical Sciences, Lund University, Lund, S-221 85, Sweden. Email: hakan.olsson@med.lu.se

Received 19 August 2015 Revised 31 October 2015 Accepted 11 November 2015 Published 26 November 2015

Citation: Olsson $\mathrm{H}$. With increasing age at tumor diagnosis in familial cancer: Cancer is limited to fewer organs. J Cancer Res Ther. 2015; 3(11):144-146. DOI:10.14312/2052-4994.2015-21

Copyright: (c) 2015 Olsson H. Published by NobleResearch Publishers. This is an open-access article distributed under the terms of the Creative Commons Attribution License, which permits unrestricted use, distribution and reproduction in any medium, provided the original author and source are credited. 
Table 1 The median age at diagnosis for melanoma $\left({ }^{*}\right)$ and breast cancer $\left({ }^{*}\right)$ in the studies referenced within the text.

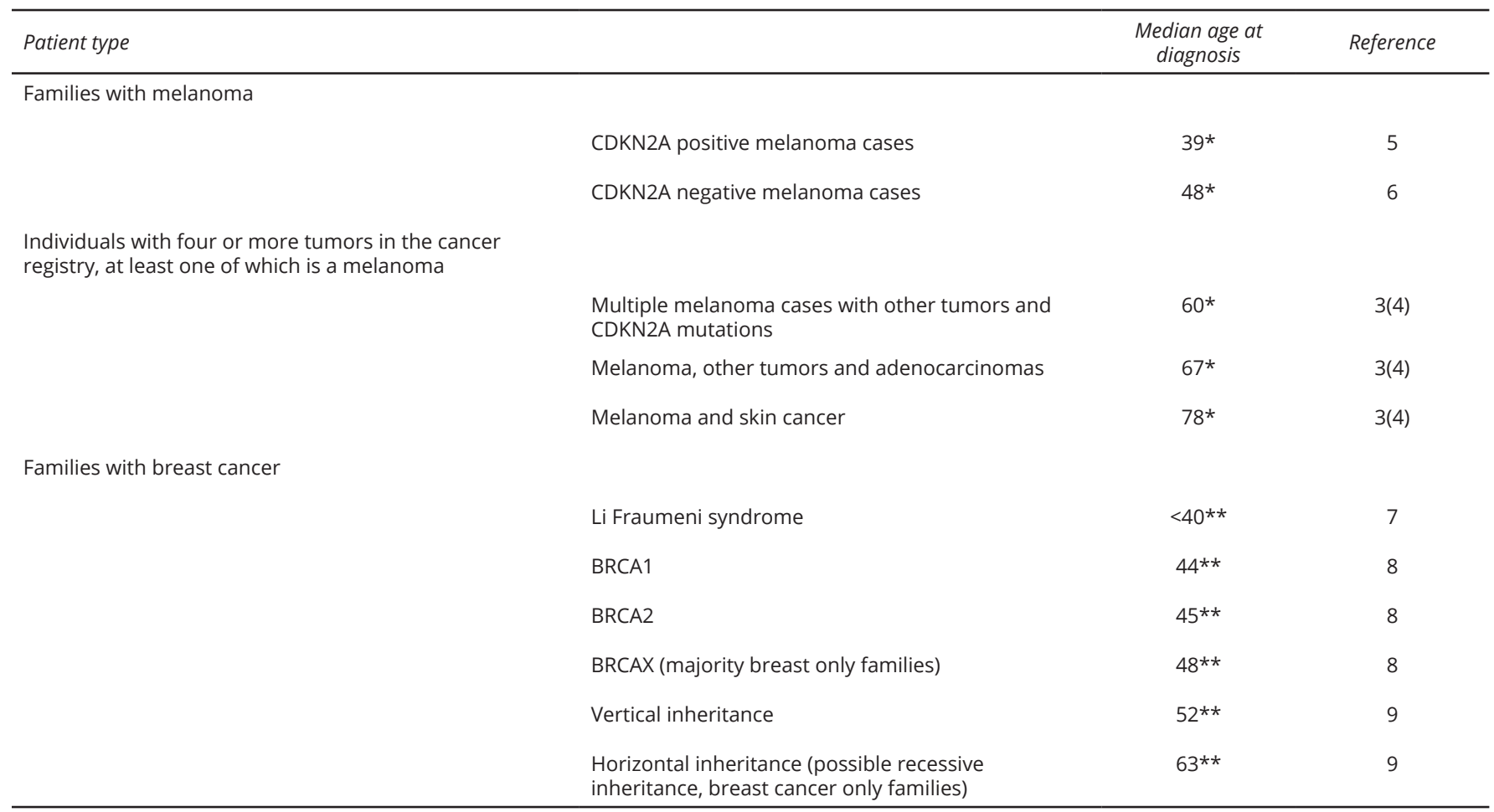

present with colon cancer alone later in life than for HNPCC families [11]. Synchronous tumors of the colon are also more common in individuals older than 65years of age [12]. Patients with endometrial cancer and associated ovarian cancer were more likely to be younger and have superficially invasive endometrial cancer, a family history of HNPCC-related tumors, and a family history of breast or ovarian cancer [13].

\section{Discussion}

In this article, the author posited that familial syndromes become more organ specific with increasing age at tumor presentation; as a result, very late in life, only a few organs are affected by tumors. One explanation could be that late in life, the tumor originates from a more differentiated, organ-specific progenitor/stem cell, while the progenitor/ stem cell might be involved in organogenesis in different organs earlier in life. An alternative explanation is that polygenic genes affect and modify the penetrance of the disease, and the tumor spectra are more important in patients who present with tumor early in life. Examples have been provided for melanoma and non-melanoma skin cancer, breast cancer, colon cancer, and endometrial cancer.

More studies of the cell of origin are needed in the familial setting to determine whether there is a different stem cell/ progenitor cell of origin for the tumors in families with early or late disease onset. There is evidence supporting that the cells populations differ in the non-familial setting of breast cancer $[14,15]$. Additionally, for cancer syndromes that present early in life, it should be determined whether the individuals who develop tumors later in life have tumors in a more restricted organ pattern. This would imply that the progenitor/stem cells with contrasting differentiation are responsible for the observations.
What is the clinical implication of the hypothesis?

It may be that older patients with a familial disease only need to be screened for cancer in a limited number of organs or in one organ. Likewise, prophylactic operations for a risk organ may be more successful or easy to undertake in older patients in whom few organs are affected. Additionally, chemoprevention, if possible, may be more effective for tumors that only involve one or a few organs.

\section{Conclusion}

Patients with familial cancer who present with cancer at an older age have a more organ-restricted disease. This could be because the tumor has a more differentiated progenitor/stem cell origin. Examples are given for families with breast cancer, melanoma, non-melanoma skin cancer, endometrial and colon cancer. To further substantiate the findings in this study, patients with other familial tumor types should be studied to determine whether the hypothesis is a generalized phenomenon. Our preliminary data support this possibility.

\section{Acknowledgement}

Acknowledge the support of grants from the Swedish Cancer Society, Swedish Research Council and ERC advanced grant 294576-risk factors cancer.

\section{Conflicts of interest}

The author has no conflicts of interest to report.

\section{References}

[1] Lichtenstein P, Holm NV, Verkasalo PK, Iliadou A, Kaprio J, et al. Environmental and heritable factors in the causation of cancer-analyses of cohorts of twins from Sweden, Denmark, and Finland. N Engl J Med. 2000; 343(2):78-85. 
[2] Lynch HT, Snyder C, Casey MJ. Hereditary ovarian and breast cancer: what have we learned? Ann Oncol. 2013; 24(Suppl 8):viii83-viii95.

[3] Nielsen K, Ingvar C, Masback A, Westerdahl J, Borg A, et al. Melanoma and nonmelanoma skin cancer in patients with multiple tumours-evidence for new syndromes in a population-based study. $\mathrm{Br}$ J Dermatol. 2004; 150(3):531-536.

[4] Nielsen K, Masback A, Bladstrom A, Lundgren L, Jonsson N, et al. Confirmed cancer trends in families of patients with multiple cancers including cutaneous melanoma. Br J Dermatol. 2008; 158(2):429-431.

[5] Helgadottir $H$, Höiom $V$, Jönsson $G$, Tuominen $R$, Ingvar $C$, et al. High Risk of Tobacco-Related cancers in CDKN2A Mutation-Positive Melanoma Families. J Med Genet. 2014; 51(8):545-552.

[6] Helgadottir $H$, Höiom V, Tuominen R, Jönsson G, Månsson-Brahme $\mathrm{E}$, et al. CDKN2A mutation negative melanoma families have an increased risk for melanoma and other skin cancers but not for other malignancies. Int J Cancer. 2015; 137(9):2220-2226.

[7] Olsson H. A hypothesis about tumour development and the clinical features of hereditary breast cancers. Eur J Cancer. 2001; 37(16):20232029.

[8] Loman N, Johannsson O, Bendahl PO, Borg A, Ferno M, et al. Steroid receptors in hereditary breast carcinomas associated with BRCA1 or BRCA2 mutations or unknown susceptibility genes. Cancer. 1998; 83(2):310-319.

[9] Ellberg C, Jonsson G, Olsson H. Can a phenotype for recessive inheritance in breast cancer be defined? Fam Cancer. 2010; 9(4):525530.

[10] Malkin D. Li-fraumeni syndrome. Genes cancer. 2011; 2(4):475-484.

[11] Ghazi S, Lindforss U, Lindberg G, Berg E, Lindblom A, et al. LowRisk Colorectal Cancer Study Group. Analysis of colorectal cancer morphology in relation to sex, age, location, and family history. J Gastroenterol. 2012; 47(6):619-634.

[12] Samadder NJ, Curtin K, WongJ, Tuohy TM, Mineau GP, et al. Epidemiology and familial risk of synchronous and metachronous colorectal cancer: a population-based study in Utah. Clin Gastroenterol Hepatol. 2014; 12(12):2078-2084.

[13] Uccella S, Cha SS, Melton LJ, Bergstralh EJ, Boardman LA, et al. Risk factors for developing multiple malignancies in patients with endometrial cancer. Int J Gynecol Cancer. 2011; 21(5):896-901.

[14] Olsson $\mathrm{H}$. Tumour biology of a breast cancer at least partly reflects the biology of the tissue/epithelial cell of origin at the time of initiation- a hypothesis. J Steroid Biochem Mol Biol. 74(2000):345-350.

[15] Olsson $H$. Cell of origin of breast cancer-an updated hypothesis merging epidemiological data with molecular biology. J Carcinogene Mutagene. 2013; (4):139. 